\title{
The musculoskeletal impairment negatively impacts the quality of life of children and adolescents with psoriasis
}

\author{
Thaís Cugler Meneghetti ${ }^{{ }^{*}} \mathbb{D}$, Thaís Mayumi Honda Padilha² ${ }^{2}$, Valderílio Feijó Azevedo ${ }^{3} \mathbb{D}$, \\ Mônica Nunes Lima Cat ${ }^{4} \mathbb{D}$, Bruna Maria Stofela Sarolli ${ }^{5}$ (D) and Vânia Oliveira de Carvalho ${ }^{6}$ (D)
}

\begin{abstract}
Background: The severity of nail disease, the presence of arthralgia and fatigue are predictors of development of psoriatic arthritis (PsA) in patients with psoriasis (Pso). In children, little is known about the musculoskeletal (MSK) impairment in patients with Pso and its effect on health-related quality of life (HRQoL).

Objectives: To determine the frequencies of pain and MSK inflammation (i.e., arthritis, enthesitis, and sacroiliitis) among children and adolescents with Pso and its relationship to HRQoL and fatigue.

Methods: Pediatric patients with Pso underwent a rheumatologic physical examination to evaluate synovitis, enthesalgia, sacroiliac joint (SIJ) pain and tender points of fibromyalgia. The core set of domains recommended by the GRAPPA - OMERACT to be measured in PsA studies was assessed. Ultrasound (US) was performed in clinical cases of enthesitis, and magnetic resonance imaging (MRI) was performed in cases of SIJ pain.

Results: Forty-three participants ( $10 \pm 2.9$ years old) were evaluated. Pain on palpation of the entheses was observed in 10 (23.2\%) patients and pain on SIJ palpation was observed in 3 (7\%). No patient presented with synovitis; one presented with enthesitis on US, but MRI did not confirm sacroiliitis in any case. Patients with MSK pain had greater skin disease severity (PASI 5.4 vs. $2, p<0.01$ ), worse fatigue, and lower HRQoL scores on all instruments used. The estimated risk of HRQoL impairment was eight times higher in the presence of MSK pain, which was an independent predictive factor. With a NAPSI greater than 30 , the probability of pain was greater than $80 \%$.
\end{abstract}

Conclusion: MSK pain is frequent among children with Pso, related to the severity of skin and nail disease, and negatively affects HRQoL. The typically used complementary exams might not detect the inflammatory process caused by Pso.

Keywords: Psoriasis, Musculoskeletal pain, Juvenile arthritis, Quality of life, Fatigue

\section{Background}

Psoriasis (Pso) and psoriatic arthritis (PsA) negatively affect the health-related quality of life (HRQoL) of children and adults $[1,2]$. The prevalence of PsA can reach $41 \%$ among adults with Pso [3] and is lower in children,

\footnotetext{
*Correspondence: thaisoul@gmail.com

'Pediatric Rheumatology, Unit of Pediatrics at Clinics Hospital, Federal University of Paraná, R. Gen. Carneiro, 181 - Alto da Glória, Curitiba, PR 80060-900, Brazil

Full list of author information is available at the end of the article
}

around 3,3\% [4]. Arthralgia and fatigue predict the development of PsA in adults with Pso [5]; however, prospective studies of rheumatic impairment in children with Pso are scarce.

The inflammatory process extends beyond the skin and joints and can compromise other systems. Children with juvenile PsA (JPsA) are at increased risk of inflammatory bowel disease, uveitis, diabetes, and depression [6].

(c) The Author(s). 2020 Open Access This article is licensed under a Creative Commons Attribution 4.0 International License, which permits use, sharing, adaptation, distribution and reproduction in any medium or format, as long as you give appropriate credit to the original author(s) and the source, provide a link to the Creative Commons licence, and indicate if changes were made. The images or other third party material in this article are included in the article's Creative Commons licence, unless indicated otherwise in a credit line to the material. If material is not included in the article's Creative Commons licence and your intended use is not permitted by statutory regulation or exceeds the permitted use, you will need to obtain permission directly from the copyright holder. To view a copy of this licence, visit http://creativecommons.org/licenses/by/4.0/. 
JPsA represents 6 to $8 \%$ of cases of juvenile idiopathic arthritis (JIA) and arthritis precedes Pso in up to half of these cases [3]. It comprises two distinct populations of patients: a group of younger children, mainly girls, with small joint involvement and antinuclear antibodies and an older group with an increase incidence of enthesitis and axial disease, which resembles spondyloarthritis (SpA) [7]. The most commonly used criteria for its classification, published by the International League of Associations for Rheumatology (ILAR) [8], are criticized for being restrictive because they exclude cases with manifestations of $\mathrm{SpA}$. The recently published revision of the criteria for JIA did not reach a consensus and postponed the definition of JPsA [9]. Because JPsA is associated with a worse prognosis than other forms of JIA [10], additional studies to better understand the characteristics of childhood-onset Pso and JPsA and a correct definition of its diagnosis is needed urgently. The present study aimed to determine the frequencies of pain and MSK inflammation (arthritis, enthesitis and sacroiliitis) among children and adolescents with Pso and its relationship with HRQoL and fatigue.

\section{Methods}

It was an observational, analytical, and cross-sectional study with prospective data collection. Children and adolescents aged 2 to 16 years in follow-up for Pso at a pediatric dermatology service were included. The exclusion criteria were the presence of overlapping skin diseases, traumatic or congenital MSK abnormalities, and cognitive impairment. The protocol of the study was developed based on the ethical standards in force and approved by the research ethics committee at Clinics Hospital from Federal University of Paraná (IRB 2.027.595). The parents and participants signed informed consent and assent documents.

Clinical information was obtained during medical interview. All patients underwent a rheumatologic physical examination that evaluated the presence of pain, joint limitation and/or swelling, pain on the palpation of the 18 tender points (TP) of fibromyalgia, pain on palpation of entheses (i.e., medial epicondyles, patella, tibia, Achilles tendon, plantar fascia insertion in the calcaneus, and fifth metatarsals), and pain on palpation of the sacroiliac joints. Patients who presented with SIJ or peripheral joint pain and limit on motion were reexamined 2 months later.

Following the recommendations of the Group for Research and Assessment of Psoriasis and Psoriatic Arthritis - Outcome Measures in Rheumatology (GRAPPA-OMERACT) working group [11] concerning the critical domains that should be included in PsA studies, suitable instruments for pediatric rheumatology validated in Brazil, were applied. The
Physician MSK (PhysMSK) visual analog scale (VAS) was used to assess MSK activity. The Psoriasis Area and Severity Index (PASI) was used to measure skin disease activity; a PASI above 5 is considered moderate-to-severe disease. The Nail Psoriasis Severity Index (NAPSI) was used to determine nail involvement, computed using a dermatoscope to improve sensitivity [12]. Pain and Patients' global assessment of disease was assessed using a VAS. Physical function was evaluated using the Childhood Health Assessment Questionnaire (CHAQ). The effect of skin disease on HRQoL was evaluated using the Children's Dermatology Life Quality Index (CDLQI). General HRQoL was measured using the Pediatric Quality of Life Inventory 4.0 (PedsQL 4.0) [1]. Fatigue was assessed using the Pediatric Quality of Life InventoryMultidimensional Fatigue Scale (PedsQL-MFS). The erythrocyte sedimentation rate (ESR) and C-reactive protein (CRP) levels measured systemic inflammation.

For patients with pain on palpation of entheses $(n=9)$, ultrasound (US) examinations were performed using an Esaote Mylab 30 with a $15-\mathrm{MHz}$ high frequency linear transducer based on previously described pediatric parameters [13]. In the presence of pain on palpation of the sacroiliac joints across two evaluations $(n=3)$, the patients underwent magnetic resonance imaging (MRI) [14] that included oblique coronal STIR image and fatsuppressed (fatsat) oblique coronal T1-weighted postcontrast image. Two radiologists specialized in the MSK system, blind to the clinical data, reviewed the exams.

The statistical analyses included the application of the Mann-Whitney U test and Fisher's exact test. A univariate logistic regression estimated the likelihood of MSK pain based on the NAPSI score, and a multivariate logistic regression identified the factors associated with poorer HRQoL, using sex, age, duration of disease, type and severity of Pso by PASI and MSK pain as covariables. For all tests, a significance level of $5 \%$ and a minimum test power of $90 \%$ were applied (Statistica 10.0, Statsoft ${ }^{\circ}$.

\section{Results}

The sample consisted of 43 children. The general characteristics of the participants, Pso and MSK findings are described in Table 1.

Despite the presence of pain on joint movement during the physical examination of seven participants, none exhibited joint swelling. Two participants (4\%) presented with pain with limited movement (unrelated to their skin lesions), but these changes spontaneously remitted; therefore, no arthritis was observed. In the 10 patients with enthesalgia, the number of painful entheses was $2.8 \pm 1.13$ on average, all of which were located in the lower limbs: patella (eight patients), tibia (four patients), 
Table 1 General features of the 43 participants, psoriasis, and the findings of the rheumatologic examination

\begin{tabular}{|c|c|}
\hline Features & n (\%) \\
\hline Female sex & $27(62.8 \%)$ \\
\hline Age (years) - mean (S.D.) & $10(2.9)$ \\
\hline \multicolumn{2}{|l|}{ Clinical forms of psoriasis } \\
\hline Plaque & $31(72.1 \%)$ \\
\hline Guttate & $21(48.8 \%)$ \\
\hline Lesions in exposed areas & $7(16.3 \%)$ \\
\hline Family history of psoriasis $^{c}$ & $15(34.9 \%)$ \\
\hline Family history of psoriatic arthritis $^{c}$ & $4(11,1 \%)$ \\
\hline Complaint of joint pain & 15 (34.9\%) \\
\hline Complaint of low back pain & $5(11.6 \%)$ \\
\hline$P A S I^{a}-$ median (min-max) & $3.6(0-30.2)$ \\
\hline NAPSI ${ }^{b}$ - median (min-max) & $11(3-36)$ \\
\hline Pain on palpation of entheses & $10(23.1 \%)$ \\
\hline$>11$ tender points & $9(20.9 \%)$ \\
\hline Joint pain on examination & $7(16.3 \%)$ \\
\hline Pain on palpation of the sacroiliac joints & $3(7 \%)$ \\
\hline
\end{tabular}

${ }^{a}$ PASI Psoriasis Area and Severity Index, ${ }^{\mathrm{b}}$ NAPSI Nail Psoriasis Severity Index In first-degree relatives and Achilles tendon (four patients). No participant was diagnosed with fibromyalgia because they did not meet the criteria of diffuse pain and somatic symptoms.

Three patients with pain in the sacroiliac joints underwent MRI, which showed no signs of sacroiliitis. A US sign of enthesitis in the calcaneus was found in one patient characterized by the presence of two Doppler spots, a moderate signal. This was the only case that was diagnosed with JPsA, due to the presence of Pso, nail involvement and documented enthesitis. The patient had complaints of recurrent MSK pain in heel and tibial region. One other patient with JPsA (Pso, arthritis and dactylitis) was identified but excluded from the analyses because he had Down Syndrome, a condition whose classification of arthritis is still debated, and he had cognitive deficits that limited his response to the questionnaires.

Patients were grouped based on the presence of MSK pain (findings on physical examination: joint pain, pain on entheses, pain on sacroiliac joints, and/or more than 11 TP), and the frequency of MSK pain was $37.2 \%(n=16)$. This group showed significantly higher skin and nail disease activity scores; higher pain VAS; worse physical function; worse HRQoL as measured by the global well-being VAS, CDLQI, and PedsQL 4.0; and greater fatigue (Table 2). The inflammation tests ESR and CRP showed no differences. When dividing the sample in patients with mild versus

Table 2 Psoriasis scores, physician's score, patient-reported outcomes among participants with or without musculoskeletal pain

\begin{tabular}{|c|c|c|c|}
\hline \multirow[t]{2}{*}{ Scores } & \multicolumn{2}{|l|}{ Groups } & \multirow{2}{*}{$\begin{array}{l}P \\
\text { value* }^{*}\end{array}$} \\
\hline & $\begin{array}{l}\text { No pain }(n=27) \\
\text { median (min-max) }\end{array}$ & $\begin{array}{l}\text { MSK }^{\text {a Pain }(n=16)} \\
\text { median (min-max) }\end{array}$ & \\
\hline$\overline{\text { PASI }^{b}}$ & $2(0-30.2)$ & $5.4(0.8-16.5)$ & $<0.01$ \\
\hline NAPSI ${ }^{\mathrm{C}}$ & $9(3-36)$ & $18(8-36)$ & $<0.001$ \\
\hline PhysMSK VAS ${ }^{d}$ & $0(0-0)$ & $1.5(0-5)$ & $<0.001$ \\
\hline Patient Global VAS & $0.5(0-5.1)$ & $3(0-9)$ & 0.04 \\
\hline Pain VAS & $0(0-5)$ & $2(0-9)$ & $<0.01$ \\
\hline $\mathrm{CHAQ}^{\mathrm{e}}$ & $0(0-0.5)$ & $0.1(0-1.4)$ & $<0.001$ \\
\hline CDLQI $\left.\right|^{f}$ & $1(0-13)$ & $6(1-21)$ & $<0.001$ \\
\hline PedsQL ${ }^{9} 4.0$ - Total Score & $85.1(63.6-100.0)$ & $69.7(10.6-94.2)$ & $<0.001$ \\
\hline PedsQL 4.0 - Physical Health & $93.7(59.4-100)$ & $71.8(12.5-96.9)$ & $<0.001$ \\
\hline PedsQL 4.0 - Emotional Functioning & $77.5(30-100)$ & $50(5-90)$ & $<0.01$ \\
\hline PedsQL 4.0 - Social Functioning & $92.5(70-100)$ & $85(20-100)$ & 0.04 \\
\hline PedsQL 4.0 - School Functioning & $80(50-100)$ & $65(5-90)$ & $<0.01$ \\
\hline PedsQL 4.0 - Psychosocial Health & $81.7(0-100.0)$ & $64.2(0-93.3)$ & $<0.01$ \\
\hline PedsQL-MFS ${ }^{h}$ - Total Fatigue & $86.8(51.4-100)$ & $60.4(6.9-8.7)$ & $<0.001$ \\
\hline PedsQL-MFS - General Fatigue & $91.6(58.3-100)$ & $64.6(12.5-100)$ & $<0.01$ \\
\hline PedsQL-MFS - Sleep/Rest Fatigue & $87.5(50-100)$ & $64.6(4.2-83.3)$ & $<0.001$ \\
\hline PedsQL-MFS - Cognitive Fatigue & $81.2(8.3-100)$ & $50.0(4.2-91.6)$ & 0.04 \\
\hline
\end{tabular}

${ }^{a}$ MSK musculoskeletal, ${ }^{b}$ PASI Psoriasis Area and Severity Index, ${ }^{c}$ NAPSI Nail Psoriasis Severity Index, ${ }^{\mathrm{d}}$ PhysMSK VAS Physician musculoskeletal Visual Analog Scale, ${ }^{\mathrm{e}} \mathrm{CHAQ}$ Childhood Health Assessment Questionnaire, ${ }^{\mathrm{f}} \mathrm{CDLQ}$ I Children Dermatology Life Quality Index, ${ }^{\mathrm{g} P e d s} \mathrm{QL}$ Pediatric Quality of Life Inventory, ${ }^{\mathrm{h}}$ PedsQL-MFS Pediatric Quality of Life Inventory- Multidimensional Fatigue Scale *Mann-Whitney $U$ test 
moderate to severe Pso (PASI > 5), the group with mild Pso presented significantly less patients with entesalgia $(13,8 \%$ vs $42,9 \%$; P 0,05$)$, with joint pain ( $3,4 \%$ vs $42,9 \%$; P 0,001 ), and less TP (Median 0 [0-16] vs 7 [0-15], P 0,02).

According to the multivariate logistic regression model, pain was an independent predictive factor of poorer HRQoL. The risk of impaired HRQoL was eight times higher in the presence of MSK pain $(\mathrm{OR}=8.64$, $95 \%$ CIs $=1.76-42.42 ; P<0.001)$. Other variables such as sex, age, duration of disease, type and even the severity of Pso did not increase the risk of HRQoL impairment $(P>0.08)$.

A higher probability of MSK pain was observed based on the NAPSI score in the univariate logistic regression. With a NAPSI score of 15 , the estimated probability of MSK pain was approximately $40 \%$, rising to more than $80 \%$ with a NAPSI score greater than $30(P<0.01)$.

\section{Discussion}

In the present study, a low frequency of JPsA but a high frequency of MSK pain was observed among children and adolescents with Pso. MSK pain was associated with greater Pso severity, nail disease, and fatigue and negatively affected HRQoL.

Approximately $35 \%$ of the participants complained of recurring joint pain, a higher frequency than the 7\% found among healthy children [15]. The number of TP (21\% with more than 11) was higher than that observed among healthy children [16]. Although the practice of quantifying TP for the diagnosis of FM is being abandoned, it was useful to show that pediatric patients with severe Pso have reduced pain thresholds. Despite the presence of recurrent MSK pain and the association with fatigue, patients did not have the characteristics of widespread pain and somatic symptoms at a level high enough to warrant the diagnosis of FM, as recommended by the 2016 revision of the ACR criteria, which is valid for individual patient diagnosis $[17,18]$.

The issue of pain in patients with PsA is somewhat complex. It is known that 9,6-27.2\% of adults with PsA have FM associated [19]. However, even without this comorbidity, adults with PsA and children with SpArelated JIA suffer from a high level of pain, whose presence often does not correlate with inflammation or radiographic measures of disease [20, 21]. The interleukin 17 (IL-17), important in PsA immunopathology, is elevated in plasma of patients with FM [22], and studies in mice show that IL-17 plays a role in pain hypersensitivity following neuropathic injury [23]. IL-17 blockade causes rapid and sustained pain relief in PsA [24]. Additional research investigating whether this is due to reduced inflammation or whether it is a direct effect of IL-17 on neuropathic pain is warranted. If children with Pso and MSK pain will progress to PsA, to FM or if the pain will disappear is something that will be verified with longitudinal follow-up of these cases. There is no data in the literature on the subject.

Enthesitis was defined by ILAR as the presence of tenderness at the insertion of a tendon, ligament, joint capsule, or fascia to bone [8]. This condition was observed in $23 \%$ of the participants in this study, a frequency higher than that in healthy children, at sites which are specific for patients with juvenile SpA [25]. Nevertheless, the detection of enthesitis via US was low, probably because it was not possible to perform the exam immediately after the initial clinical evaluation. However, physical examination and US conclusions can differ, both in adults and children. Weiss et al. evaluated the characteristics of enthesitis on US and the accuracy of physical examinations for its detection among 30 children with enthesitis-related arthritis (ERA); these authors observed that pain on palpation of entheses had a low positive and negative predictive value for enthesitis as confirmed by US [13].

Although participants in this study presented with complaints of low back pain and pain on palpation of the SIJ, they did not present sacroiliitis on MRI, the gold standard exam for detecting inflammatory sacroiliitis. Weiss et al. evaluated the presence of sacroiliitis among 40 children with early SpA (ERA and JPsA) using MRI as the standard reference [14]. They found that eight patients had active sacroiliitis; of these, only three (38\%) reported histories of low back pain or pain on palpation of the joint. The authors concluded that neither the definition of sacroiliitis used by the ILAR (pain on palpation of the SIJ) nor the definition of the Assessment of SpondyloArthritis International Society (ASAS) for the presence of axial involvement in patients with SpA (which requires the presence of back pain) show adequate performance for application to juvenile SpA. The absence of MRI findings in the present study, reinforce this concept and suggests that pain on entheses and SIJ during physical examination is insufficient to define inflammation in these sites among pediatric patients with Pso. It is also possible that these patients present inflammation not detectable by the laboratorial and imaging methods used.

For the definition of the diagnosis of JPsA, complementary exams were considered to ensure greater specificity. It was also followed the concept of PsA in adults, which considers the disease as a spectrum of SpA, with potential axial and enthesitic involvement, since it has already been demonstrated that children and adolescents can have this type of disease presentation [26]. Zisman et al. showed that the use of the Classification criteria for Psoriatic Arthritis (CASPAR) increases the detection of pediatric patients with JPsA who are not being identified by the ILAR criteria [27]. The validation of CASPAR 
criteria in pediatric rheumatology could be a resource to favor the unification of the PsA classification across age spectrum, would better reflect the pathogenesis of the disease and facilitate its study, and could improve the continuity of care in the transition from childhood to adulthood [28]. Low frequency of JPsA was found in the present study, as expected, since the prevalence of PsA in patients with Pso is lower in children than in adults [4] and the sample size was small.

HRQoL impairment was significantly higher among participants with MSK impairment. The fact that the severity of Pso did not contribute (in the logistic regression model) to a worse HRQoL, only the MSK impairment, highlights the need for a new look at how psoriatic disease affects the life of the pediatric patient. Studies of adults have shown that PsA causes worse HRQoL scores than Pso alone [29]. Children with SpA-related JIA diseases (ERA and JPsA) experience more pain as well as poorer HRQoL than children with other forms of JIA [21]. The core measures recommended by the GRAPPA-OMERACT for PsA studies proved useful for assessing children and adolescents with Pso in a broad and multidimensional manner.

Fatigue was also significantly higher among patients with Pso and MSK pain and a higher NAPSI score predicted greater likelihood of MSK pain. These findings are unprecedented in children with Pso and reinforces the hypothesis that the inflammatory process of psoriatic disease acts systemically even before the development of PsA. Given that nail disease predicts joint disease and can occur years before the establishment of PsA [30], children and adolescents with Pso and nail involvement should be monitored for the development of JPsA, especially in cases with recurrent MSK pain.

The limitations of this study include its small sample size, that limits the extrapolation of the results, and the absence of a healthy control group, which was minimized by comparing patients with minimal cutaneous disease activity to those with moderate to severe disease. The cross-sectional design of this study prevents the observation of case progression, a longitudinal design would be useful for defining predictive factors of JPsA development.

\section{Conclusions}

Our results have shown that MSK pain is frequent among children and adolescents with Pso, is related to the severity of skin and nail disease, and to fatigue. MSK impairment was responsible for a poorer HRQoL. Research to improve the accuracy of instruments to measure inflammation needs to evolve to fill the gaps between patients' pain complaints and what is found in laboratory and imaging tests. Multidisciplinary Pso care is relevant and monitoring of these patients for the development of JPsA is needed.

\section{Acknowledgements}

Not applicable.

\section{Authors' contributions}

TCM project; data collection; bibliographic revision; paper draft. TMHP data collection; bibliographic revision. VFA project; US images; paper draft; paper review. MLNC statistical analysis; paper review. BMSS MRI images review; paper review. VOC project; data collection; paper draft; paper review. All authors read and approved the final manuscript. All authors gave consent for publication.

\section{Funding}

This work was supported by the Scientific Initiation Program of the Conselho Nacional de Desenvolvimento Científico e Tecnológico (CNPq) [grant number 2017023771]

\section{Availability of data and materials}

The datasets used and/or analysed during the current study are available from the corresponding author on reasonable request.

\section{Ethics approval and consent to participate}

Ethical approval in Research Ethics Committee at Clinics Hospital from Federal University of Paraná: 2.027.595.

\section{Consent for publication}

Not applicable.

\section{Competing interests}

The authors declare that they have no competing interests.

\section{Author details}

${ }^{1}$ Pediatric Rheumatology, Unit of Pediatrics at Clinics Hospital, Federal University of Paraná, R. Gen. Carneiro, 181 - Alto da Glória, Curitiba, PR 80060-900, Brazil. ²Medical Student, Federal University of Paraná, Curitiba, Paraná, Brazil. ${ }^{3}$ Rheumatology Division of the Department of Internal Medicine, Federal University of Paraná, Curitiba, Paraná, Brazil. ${ }^{4}$ Statistics Unit of the Department of Pediatrics, Federal University of Paraná, Curitiba, Paraná, Brazil. ${ }^{5}$ Musculoskeletal Radiologist at Clinics Hospital, Federal University of Paraná, Curitiba, Paraná, Brazil. ${ }^{6}$ Pediatric Dermatology Division of the Department of Pediatrics, Federal University of Paraná, Curitiba, Paraná, Brazil.

Received: 22 January 2020 Accepted: 5 June 2020

Published online: 17 June 2020

\section{References}

1. Varni JW, Globe DR, Gandra SR, Harrison DJ, Hooper M, Baumgartner S. Health-related quality of life of pediatric patients with moderate to severe plaque psoriasis: comparisons to four common chronic diseases. Eur J Pediatr. 2012;171(3):485-92.

2. Husni ME, Merola JF, Davin S. The psychosocial burden of psoriatic arthritis. Semin Arthritis Rheum. 2017:47(3):351-60.

3. Ogdie A, Weiss P. The epidemiology of psoriatic arthritis. Rheum Dis Clin N Am. 2015;41(4):545-68.

4. Alinaghi F, Calov M, Kristensen LE, Gladman DD, Coates LC, Jullien D, et al. Prevalence of psoriatic arthritis in patients with psoriasis: a systematic review and meta-analysis of observational and clinical studies. J Am Acad Dermatol. 2019;1:251-65

5. Eder L, Polachek A, Rosen CF, Chandran V, Cook R, Gladman DD. The development of psoriatic arthritis in patients with psoriasis is preceded by a period of nonspecific musculoskeletal symptoms: a prospective cohort study. Arthritis Rheumatol. 2017;69(3):622-9.

6. Brandon TG, Manos CK, Xiao R, Ogdie A, Weiss PF. Pediatric psoriatic arthritis: a population- based cohort study of risk factors for onset and subsequent risk of inflammatory comorbidities. J Psoriasis Psoriatic Arthritis. 2018;3(4):131-6.

7. Stoll ML, Zurakowski D, Nigrovic LE, Nichols DP, Sundel RP, Nigrovic PA. Patients with juvenile psoriatic arthritis comprise two distinct populations. Arthritis Rheum. 2006;54(11):3564-72.

8. Petty RE, Southwood TR, Manners P, Baum J, Glass DN, Goldenberg J, et al. International league of associations for rheumatology classification of 
juvenile idiopathic arthritis: second revision, Edmonton, 2001. J Rheumatol. 2004;31(2):390-2.

9. Martini A, Ravelli A, Avcin T, Beresford MW, Burgos-Vargas R, Cuttica R, et al. Toward new classification criteria for juvenile idiopathic arthritis: first steps, pediatric rheumatology international trials organization international consensus. J Rheumatol. 2019:46(2):190-7.

10. Flatø B, Lien G, Smerdel-Ramoya A, Vinje O. Juvenile psoriatic arthritis: Longterm outcome and differentiation from other subtypes of juvenile idiopathic arthritis. J Rheumatol. 2009;36(3):642-50

11. Ogdie A, De Wit M, Duffin KC, Campbell W, Chau J, Coates LC, et al. Defining outcome measures for psoriatic arthritis: a report from the GRAPPA-OMERACT working group. J Rheumatol. 2017;44(5):697-700

12. Uber M, Carvalho VO, Abagge KT, Robl Imoto R, Werner B. Clinical features and nail clippings in 52 children with psoriasis. Pediatr Dermatol. 2018;35(2):202-7.

13. Weiss PF, Chauvin NA, Klink AJ, Localio R, Feudtner C, Jaramillo D, et al. Detection of enthesitis in children with Enthesitis-related arthritis: dolorimeter examination compared to ultrasonography. Arthritis Rheumatol. 2014;66(1):218-27.

14. Weiss PF, Xiao R, Biko DM, Chauvin NA. Sacroiliitis at diagnosis of juvenile spondyloarthritis assessed by radiography, magnetic resonance imaging, and clinical examination. Arthritis Care Res. 2016;68(2):187-94.

15. Rossetto EG, Pimenta CA de M. Prevalência e caracterização da dor recorrente em escolares na cidade de Londrina. Cienc Cuid Saúde. 2012; 11(5):211-9. https://doi.org/10.4025/cienccuidsaude.v11i5.17078 Disponível em: http://periodicos.uem.br/ojs/index.php/CiencCuidSaude/article/view/ 17078.

16. Buskila D, Press J, Gedalia A, Klein M, Neumann L, Boehm RSS. Assessment of nonarticular tenderness and prevalence of fibromyalgia in children. $J$ Rheumatol. 1993;20(2):368-70.

17. Wolfe F, Clauw DJ, Fitzcharles MA, Goldenberg DL, Häuser W, Katz RL, et al. 2016 revisions to the 2010/2011 fibromyalgia diagnostic criteria. Semin Arthritis Rheum. 2016;46(3):319-29.

18. Ting TV, Barnett K, Lynch-Jordan A, Whitacre C, Henrickson M, Kashikar-Zuck S. 2010 American College of Rheumatology Adult Fibromyalgia Criteria for use in an adolescent female population with juvenile fibromyalgia. J Pediatr. 2016:169:181-7.

19. Duffield SJ, Miller N, Zhao S, Goodson NJ. Concomitant fibromyalgia complicating chronic inflammatory arthritis: a systematic review and metaanalysis. Rheumatology (Oxford). 2018;57(8):1453-60.

20. McGonagle DG, Mclnnes IB, Kirkham BW, Sherlock J, Moots R. The role of IL17A in axial spondyloarthritis and psoriatic arthritis: recent advances and controversies. Ann Rheum Dis. 2019;78(9):1167-78.

21. Taxter AJ, Wileyto EP, Behrens EM, Weiss PA. Patient reported outcomes across categories of juvenile idiopathic arthritis. J Rheumatol. 2015;42(10): 1914-21.

22. Pernambuco AP, Schetino LPL, Alvim CC, Murad CM, de Souza V, de Souza Cota Carvalho L, et al. Increased levels of il-17a in patients with fibromyalgia. Clin Exp Rheumatol. 2013;31(SUPPL.79):60-3.

23. Kim CF, Moalem-Taylor G. Interleukin-17 contributes to neuroinflammation and neuropathic pain following peripheral nerve injury in mice. J Pain. 2011; 12(3):370-83.

24. Mclnnes IB, Mease PJ, Schett G, Kirkham B, Strand V, Williams N, et al. Secukinumab provides rapid and sustained pain relief in psoriatic arthritis over 2 years: results from the FUTURE 2 study. Arthritis Res Ther. 2018;20(1):1-9.

25. Sherry DD, Sapp AP. Enthesalgia in childhood: site-specific tenderness in healthy subjects and in patients with seronegative enthesopathic arthropathy. J Rheumatol. 2003;30(6):1335-40.

26. Stoll ML, Punaro M. Psoriatic juvenile idiopathic arthritis: a tale of two subgroups. Curr Opin Rheumatol. 2011;23(5):437-43.

27. Zisman D, Gladman DD, Stoll ML, Strand V, Lavi I, Hsu JJ, et al. The juvenile psoriatic arthritis cohort in the CARRA registry: clinical characteristics, classification, and outcomes. J Rheumatol. 2017:44(3):342-51.

28. Zisman D, Stoll ML, Aviel YB, Mellins ED. Juvenile psoriatic arthritis: a report from the GRAPPA 2017 annual meeting. J Rheumatol. 2018;45:11-6.

29. Rosen CF, Mussani F, Chandran V, Eder L, Thavaneswaran A, Gladman DD. Patients with psoriatic arthritis have worse quality of life than those with psoriasis alone. Rheumatology. 2012;51(3):571-6.

30. Scher JU, Ogdie A, Merola JF, Ritchlin C. Preventing psoriatic arthritis: focusing on patients with psoriasis at increased risk of transition. Nat Rev Rheumatol. 2019;15(3):153-66.

\section{Publisher's Note}

Springer Nature remains neutral with regard to jurisdictional claims in published maps and institutional affiliations.

\section{Ready to submit your research? Choose BMC and benefit from:}

- fast, convenient online submission

- thorough peer review by experienced researchers in your field

- rapid publication on acceptance

- support for research data, including large and complex data types

- gold Open Access which fosters wider collaboration and increased citations

- maximum visibility for your research: over $100 \mathrm{M}$ website views per year

At BMC, research is always in progress.

Learn more biomedcentral.com/submissions 